\title{
Oxidative Transformation of Aminodinitrotoluene Isomers by Multicomponent Dioxygenases
}

\author{
GLENN R. JOHNSON, ${ }^{1}$ BARTH F. SMETS, ${ }^{2}$ AND JIM C. SPAIN ${ }^{1 *}$ \\ Air Force Research Laboratory, Tyndall Air Force Base, Florida, ${ }^{1}$ and Department of Civil and Environmental \\ Engineering, University of Connecticut, Storrs, Connecticut ${ }^{2}$
}

Received 7 May 2001/Accepted 11 September 2001

\begin{abstract}
The electron-withdrawing nitro substituents of 2,4,6-trinitrotoluene (TNT) make the aromatic ring highly resistant to oxidative transformation. The typical biological transformation of TNT involves reduction of one or more of the nitro groups of the ring to produce the corresponding amine. Reduction of a single nitro substituent of TNT to an amino substituent increases the electron density of the aromatic nucleus considerably. The comparatively electron-dense nuclei of the aminodinitrotoluene (ADNT) isomers would be expected to be more susceptible to oxygenase attack than TNT. The hypothesis was tested by evaluating three nitroarene dioxygenases for the ability to hydroxylate the ADNT isomers. The predominant reaction was dioxygenation of the ring to yield nitrite and the corresponding aminomethylnitrocatechol. A secondary reaction was benzylic monooxygenation to form aminodinitrobenzyl alcohol. The substrate preferences and catalytic specificities of the three enzymes differed considerably. The discovery that the ADNT isomers are substrates for the nitroarene dioxygenases reveals the potential for extensive bacterial transformation of TNT under aerobic conditions.
\end{abstract}

The manufacture of 2,4,6-trinitrotoluene (TNT) for use in military and industrial explosives and its disposal have resulted in extensive environmental contamination. Most contamination is limited to manufacture and disposal sites, but it is still problematic, since TNT persists in the environment for long periods, is acutely toxic, and is readily transformed into carcinogenic compounds (13). Current strategies for remediation of TNT-contaminated soil involve a number of practices, including chemical treatment, physical processes, land farming, phytoremediation, and other combined biological processes $(1,16$, $31)$. However, no current treatment short of incineration is widely used for complete detoxification and mineralization of TNT.

The most common biological transformation of TNT is nonspecific reduction of the nitro substituents (Fig. 1A) via the sequential addition of three electron pairs to reduce a nitro group to a nitroso group, a hydroxylamino group, and finally an amino group (30). Under strictly anaerobic conditions, all three nitro substituents can be reduced to the amine $(5,18)$. In aerobic systems, partially reduced products accumulate. The predominant products under aerobic conditions are the aminodinitrotoluene (ADNT) isomers and, to a lesser extent, 2,4diamino-6-nitrotoluene and azoxytetranitrotoluenes (4, 5, 12, $17,24,39)$. A productive reduction of TNT is catalyzed by the nitrate ester reductase from Enterobacter cloacae PB2. The reduction leads to liberation of nitrite and allows the strain to grow using TNT as the sole nitrogen source (9).

Previous work defined the oxidative pathways for biodegradation of nitrobenzene and 2,4-dinitrotoluene (2,4-DNT) (19, 32). The initial step in each case is dihydroxylation of the aromatic ring (Fig. 1B and C); the nitro substituent then serves as an anionic leaving group in the reaction to produce the

\footnotetext{
* Corresponding author. Mailing address: AFRL/MLQL, 139 Barnes Dr.-Suite 2, Tyndall AFB, FL 32403. Phone: (850) 283-6058. Fax: (850) 283-6223. E-mail: jim.spain@tyndall.af.mil.
}

corresponding catechol. The genes encoding nitroarene dioxygenases have been cloned from Burkholderia sp. strain DNT (35), Comamonas sp. strain JS765 (D. J. Lessner, G. R. Johnson, R. E. Parales, J. C. Spain, and D. T. Gibson, submitted for publication), and Burkholderia cepacia R34 (B. E. Haigler, C. C. Somerville, J. C. Spain, and R. K. Jain, Abstr. 97th Gen. Meet. Am. Soc. Microbiol., abstr. Q343, 1997). The three nitroarene dioxygenases have high amino acid sequence identity, but the substrate preference and catalytic specificity of the enzymes differ despite their sequence similarity (22; Lessner et al., submitted).

Various oxygenases catalyze oxidation of the methyl substituent of nitroarenes. It can be a productive reaction, as in the pathways for 4-nitrotoluene degradation in Pseudomonas sp. strain 4NT (11) and Pseudomonas sp. strain TW3 (25). Many oxygenases gratuitously transform the methyl group on nitroarenes to the corresponding benzyl alcohol $(6,20,26)$. Other reports describe biological oxidation of TNT. Pseudomonas sp. strain JLR11 transforms TNT to 2,4,6-trinitrobenzaldehyde (7). Bruns-Nagel et al. (3) found 2,4,6-trinitrobenzoate in extracts obtained from TNT-contaminated soils, although they could not define the source of the oxidant in the complex system.

Structurally, TNT is similar to 2,4-DNT and 2,6-DNT, which suggests that the dioxygenases that catalyze the oxidation of dinitrotoluenes could also hydroxylate TNT. However, no compelling evidence of oxygenolytic removal of the nitro groups of TNT has been reported. Oxidative attack on the ring appears to be severely hampered by the combined electronwithdrawing effects of the three nitro substituents. The partial reduction of TNT to 2- or 4-ADNT creates an electron-donating amino group on the ring in place of the electron-withdrawing nitro group. The increase in electron density of the ring should increase the potential for electrophilic attack by dioxygenase enzymes (15).

The aim of the present study was to test the hypothesis that 


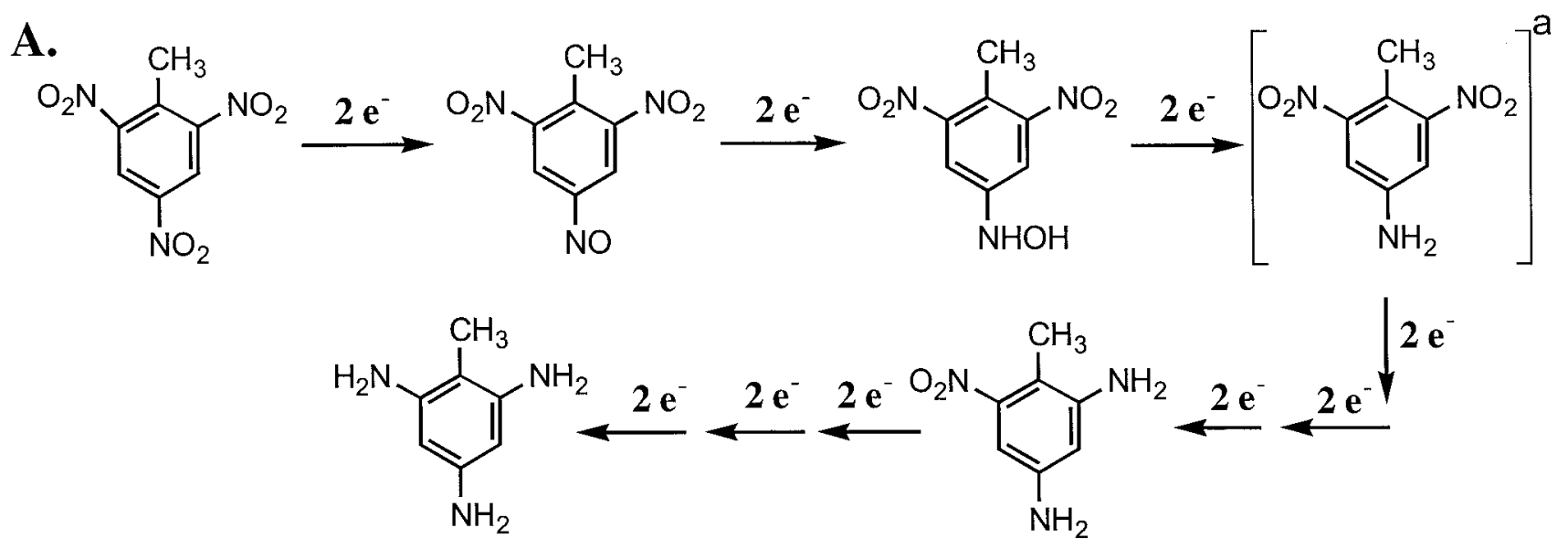

B.<smiles>O=[N+]([O-])c1ccccc1O</smiles>

C.<smiles>Cc1ccc([N+](=O)[O-])cc1[N+](=O)[O-]</smiles><smiles>Cc1cc(O)c(O)cc1[N+](=O)[O-]</smiles><smiles>CCC</smiles><smiles>CC1=CC(=O)C(O)=CC1=O</smiles><smiles>Cc1cc(O)c(O)cc1O</smiles>

FIG. 1. (A) Pathway for bacterial reduction of TNT (30). The monoamino compounds are typical stable end products under aerobic conditions. Further reduction generally requires lower redox potentials (17). (B) Oxidative transformation of nitrobenzene to catechol in the nitrobenzene pathway from strain JS765 (19). (C) Oxidative pathway for 2,4-DNT degradation (32). The initial transformation is catalyzed by 2,4-DNT dioxygenase. a, 2A46DNT is formed in equivalent reactions.

partial reduction of TNT to ADNT isomers makes the aromatic ring susceptible to attack by multicomponent nitroarene dioxygenases. Oxygenolytic transformation of 2-amino-4,6-dinitrotoluene (2A46DNT) and 4-amino-2,6-dinitrotoluene (4A26DNT) was evident from transformation of ADNT to a dihydroxylated aromatic compound with concomitant evolution of nitrite. The oxidation of the ADNT isomers and identification of the hydroxylated products suggests that the electronic nature of TNT rather than steric hindrance is primarily responsible for its resistance to attack by nitroarene dioxygenases. The partial reduction of TNT to ADNT, followed by dioxygenation of the ADNT, could account for significant transformation of TNT under aerobic conditions.

\section{MATERIALS AND METHODS}

Bacterial strains, plasmids, and growth conditions. Escherichia coli DH5 $\alpha$ was the host strain for recombinant plasmids containing the oxygenase genes. Bacteria were grown in Luria-Bertani medium (Difco Inc., Detroit, Mich.) containing glycerol $(0.5 \%)$ and ampicillin $(100 \mathrm{mg} /$ liter $)$ or kanamycin $(50 \mathrm{mg} / \mathrm{liter})$ to maintain plasmid selection. The genes encoding the dioxygenase operons were cloned into various vectors under control of the lac promoter to allow regulated gene expression. The 2,4-DNT dioxygenase from strain DNT was cloned within vector pGEM7f (Promega, Inc., Madison, Wis.) as a 6.8-kb NsiI restriction fragment to yield plasmid pJS48 (34). The 2,4-DNT dioxygenase from strain R34 was cloned on a 5.6-kb $S a c \mathrm{I} / E c o \mathrm{RV}$ fragment from pJS329a (Haigler et al., Abstr. 97th Gen. Meet. Am. Soc. Microbiol., 1997) into vector pK18 (23) to yield plasmid pJS1329. The recombinant plasmid pDTG927 served as the source for nitrobenzene dioxygenase (Lessner et al., submitted). Plasmid pDTG927 con- tains a 4.5-kb DNA fragment from Comamonas sp. strain JS765 (19) cloned into vector $\mathrm{pUC18}$

Transformation of aminodinitrotoluene. E. coli $\mathrm{DH} 5 \alpha$ strains were grown in Luria-Bertani medium-glycerol at $30^{\circ} \mathrm{C}$ with shaking to an $A_{600}$ of 0.4 to 0.6 , and then isopropyl- $\alpha$-D-thiogalactopyranoside (IPTG; $1 \mathrm{mM}$ ) was added to induce synthesis of the oxygenase. After $4 \mathrm{~h}$, the cells were harvested by centrifugation, washed in phosphate buffer (20 mM; pH 7.5), and then suspended in buffer.

Transformation assays were done in triplicate in 125 -ml baffled flasks containing cells (final $A_{600}, 0.3$ to 0.5 ), $10 \mathrm{ml}$ of phosphate buffer with pyruvate ( $1 \mathrm{mM}$ ), and the aminodinitrotoluene substrates $(25 \mu \mathrm{M})$. The suspensions were incubated with shaking $\left(250 \mathrm{rpm} ; 30^{\circ} \mathrm{C}\right)$, and samples were collected at appropriate intervals for high-performance liquid chromatography (HPLC) and nitrite analysis to monitor the progress of the reaction. The reaction was stopped by mixing the samples with one-fifth volume of acetonitrile and centrifuging the mixture to remove the cells. Reaction rates were estimated from the initial slopes of the substrate disappearance curves.

The samples $(25 \mathrm{ml})$ for gas chromatography-mass spectrometry analyses were obtained from cell suspensions that had been incubated with ADNT for 4 to $12 \mathrm{~h}$. Following incubation, the cells were removed by centrifugation and the aqueous phase was acidified to $\mathrm{pH} 2.5$. The reaction products were extracted three times with $8 \mathrm{ml}$ of ethyl acetate (previously washed with $1 \mathrm{~N} \mathrm{NaOH}$ ). The organic phase was dried over anhydrous sodium sulfate, the solvent was evaporated under nitrogen, and the residue was dissolved in acetonitrile.

Larger quantities of the putative 3-amino-4-methyl-5-nitrocatechol (3A4M5NC) were produced by incubating $2 \mathrm{~A} 46 \mathrm{DNT}$ with $E$. coli DH5 $\alpha$ (pJS48) until the 2A46DNT was depleted. The 3A4M5NC was collected from reaction supernatants on a $\mathrm{C}_{18} 35 \mathrm{~cm}^{3}$ solid-phase extraction cartridge (Millipore, Milford, Mass.) and eluted from the matrix with methanol-water (50:50). The eluate was diluted to $20 \%$ methanol, acidified to $\mathrm{pH} 2.5$, and extracted with ethyl acetate. The ethyl acetate was removed under vacuum, and the product purity was confirmed by HPLC. The 3A4M5NC gave UV-visible light absorbance maxima at $459 \mathrm{~nm}(\varepsilon=$ 

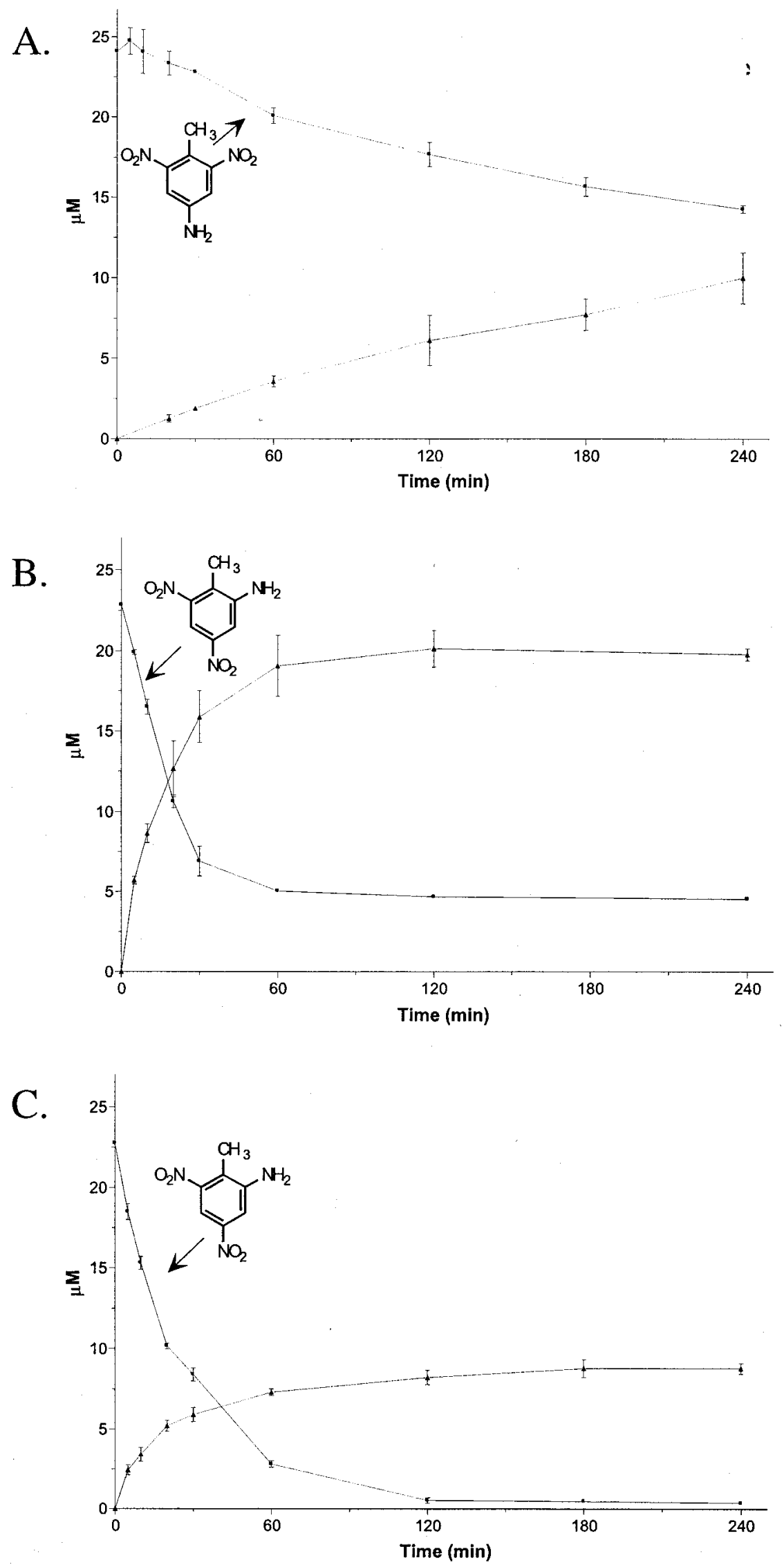

FIG. 2. Transformation of ADNTs by nitroarene dioxygenases. The data are averages of triplicate reactions. $\mathbf{a}, 4 \mathrm{~A} 26 \mathrm{DNT}$ (A) and 2A46DNT (B and C); $\boldsymbol{\Delta}$, nitrite. (A) Nitrobenzene dioxygenase [E. coli DH5 (pDTG927)]; $0.15 \mathrm{mg}$ of protein $\mathrm{ml}^{-1}$. (B) 2,4-DNT dioxygenase from strain DNT [E. coli DH5 $\alpha$ (pJS48)]; $0.08 \mathrm{mg}$ of protein $\mathrm{ml}^{-1}$. (C) 2,4-DNT dioxygenase from strain R34 [E. coli DH5 $\alpha(\mathrm{pJS} 1329)$ ]; $0.13 \mathrm{mg}$ of protein ml ${ }^{-1}$. 
4,130 $\left.\mathrm{M}^{-1}\right)$ and $207 \mathrm{~nm}\left(\varepsilon=17,140 \mathrm{M}^{-1}\right)$ with a slight shoulder at $230 \mathrm{~nm}$ in water at $\mathrm{pH} 7.0$.

Analytical methods. HPLC analysis was done with a Hewlett-Packard (Santa Clarita, Calif.) model 1050 chromatography system equipped with a model 1040 $\mathrm{M}$ diode array detector. Compounds were separated on a Supelcosil LCABZ+Plus column (25 by $4.6 \mathrm{~mm}$ ) (Supelco, Bellefonte, Pa.) with a mobile phase of acetonitrile- $0.1 \%$ trifluoroacetic acid $\left(1 \mathrm{ml} \mathrm{min}^{-1}\right)$. The mobile phase was held at $25 \%$ acetonitrile for $6 \mathrm{~min}$, increased to $60 \%$ acetonitrile over $1 \mathrm{~min}$, held at $60 \%$ acetonitrile for $8 \mathrm{~min}$, and then returned to initial conditions. The UV absorbance was monitored at 230 and $330 \mathrm{~nm}$.

Trimethylsilyl derivatives were prepared with N,O-bis(trimethylsilyl)-trifluoroacetamide (BSTFA; Alltech Associates Inc., Deerfield, Ill.) according to methods provided by the distributor. Gas chromatography-mass spectrometry analyses were done on a Hewlett-Packard series 5971 mass spectrometer and HewlettPackard model 5890 gas chromatograph with an HP-5 M.S. capillary column (30 $\mathrm{m}$ by $0.25 \mathrm{~mm} ; 0.25-\mu \mathrm{m}$ film thickness; Hewlett-Packard). Helium was the carrier gas at a constant flow rate of $0.8 \mathrm{ml} \mathrm{min}{ }^{-1}$; the injector and transfer line temperatures were 280 and $300^{\circ} \mathrm{C}$, respectively. The chromatography program was as follows: initial column temperature of $100^{\circ} \mathrm{C}$ for $1 \mathrm{~min}$, increased at $10^{\circ} \mathrm{C}$ $\min ^{-1}$ to $300^{\circ} \mathrm{C}$, and isothermal for $10 \mathrm{~min}$. The ionization voltage and electron multiplier settings were $70 \mathrm{eV}$ and $2,000 \mathrm{~V}$, respectively.

Nitrite concentrations were measured using standard methods (28). Protein concentrations were determined using the bicinchoninic acid protein assay (Pierce, Rockford, Ill.) (29).

Chemicals. 2A46DNT and 4A26DNT were from Accustandards Inc. (New Haven, Conn.); other chemicals were from Aldrich Chemicals (Milwaukee, Wis.).

\section{RESULTS AND DISCUSSION}

Transformation of ADNT. In preliminary experiments, ADNT isomers were transformed by recombinant $E$. coli strains carrying genes for nitroarene dioxygenases (data not shown). The nitrobenzene dioxygenase appeared to hydroxylate both the 2-amino- (2A46DNT) and 4-amino-dinitrotoluene (4A26DNT) isomers. However, nitrite only accumulated in reactions with $4 \mathrm{~A} 26 \mathrm{DNT}$ as the substrate. A single product was found during analysis of the ethyl acetate extract from 2A46DNT reaction mixtures. The mass spectrum of the derivatized reaction product (retention time $\left[\mathrm{R}_{\mathrm{t}}\right], 11.3 \mathrm{~min}$; predominant ions $[\mathrm{m} / \mathrm{z}], 285,270,222,195,176,149,75,73$ [trimethylsilane]) was consistent with oxidation of the methyl substituent of the ring to yield 2-amino-4,6-dinitrobenzyl alcohol. The BSTFA-derivatized compound gave a molecular ion of 285 atomic mass units (amu), consistent with the monohydroxylated 2A46DNT derivatized at a single functional group. Monooxygenation of the methyl substituent of nitroaromatic compounds is commonly catalyzed by multicomponent dioxygenases $(21,26)$. The mass spectrum of the reaction product, previously described reactions of multicomponent dioxygenases, and absence of any nitrite accumulation were consistent with benzylic hydroxylation of 2A46DNT rather than with attack on the aromatic ring. 2,4-DNT dioxygenases did not hydroxylate 4A26DNT but did transform 2A46DNT with concomitant accumulation of nitrite, which provided presumptive evidence for dioxygenation of the substrate. Subsequent experiments, therefore, focused on substrate-enzyme combinations that showed evidence for dioxygenation of the substrate.

Initial transformation rates differed substantially among the strains expressing the different oxygenases. 4A26DNT was

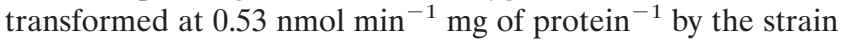
carrying the nitrobenzene dioxygenase genes, and 2A46DNT was transformed at $9.26 \mathrm{nmol} \mathrm{m^{-1 }} \mathrm{mg}$ of protein ${ }^{-1}$ by the strain carrying the 2,4-DNT dioxygenase genes from strain

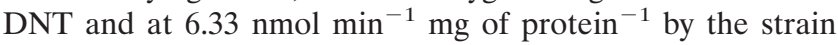

TABLE 1. Dioxygenase specific activity for recombinant $E$. coli strains carrying the nitroarene dioxygenases

\begin{tabular}{|c|c|c|c|c|c|}
\hline \multirow[b]{2}{*}{ Dioxygenase (strain) } & \multicolumn{4}{|c|}{$\mathrm{Sp} \mathrm{act}^{a}$} & \multirow{2}{*}{$\begin{array}{l}\text { Relative } \\
\text { activity }\end{array}$} \\
\hline & $\begin{array}{c}\text { Nitro- } \\
\text { benzene }\end{array}$ & $\begin{array}{l}2,4- \\
\text { DNT }^{b}\end{array}$ & $\begin{array}{c}2- \\
\text { ADNT }^{c}\end{array}$ & $\begin{array}{c}4- \\
\text { ADNT }^{c}\end{array}$ & \\
\hline Nitrobenzene dioxygenase & 4.6 & & & 0.87 & 0.19 \\
\hline 2,4-DNT dioxygenase (DNT) & & 15.2 & 4.4 & & 0.23 \\
\hline 2,4-DNT dioxygenase (R34) & & 22.2 & 5.4 & & 0.24 \\
\hline
\end{tabular}

${ }^{a}$ Nanomoles of nitrite per minute per milligram of protein.

b $50 \mu \mathrm{M}$.

${ }^{c} 25 \mu \mathrm{M}$.

carrying the 2,4-DNT dioxygenase genes from strain R34 (Fig. 2). E. coli $\mathrm{DH} 5 \alpha$ did not catalyze transformation of either ADNT isomer. No further experiments were done to optimize oxygenase activities for the individual strains. Additional assays compared dioxygenase activities with ADNT and the physiological substrate of each oxygenase (Table 1). The range of relative activities was narrow, which suggested that the oxygenases had comparable preferences for their respective ADNT isomers.

ADNT disappearance coincided with accumulation of nitrite in the reaction supernatant. Substrate disappearance and nitrite accumulation were stoichiometric in reactions catalyzed by the nitrobenzene dioxygenase (Fig. 2A) and 2,4-DNT dioxygenase (Fig. 2B) from strain DNT. The ratios of nitrite accumulation to substrate loss measured over the time course reactions were 1.00 and 0.98 , respectively. In contrast, the ratio of nitrite accumulation to substrate loss was 0.42 for the reaction catalyzed by the 2,4-DNT dioxygenase from strain R34 (Fig. 2C). The discrepancy suggested that oxidative transformation of 2A46DNT by the dioxygenase from strain R34 was not limited to hydroxylation of the aromatic ring. The ratios of 3-amino-4-methyl-5-nitrocatechol to substrate loss were 1.07 and 0.50 for the reactions with the 2,4-DNT dioxygenases from strains DNT and R34, respectively, consistent with that predicted from nitrite concentration.

Identification of products. The recombinant strain carrying the nitrobenzene dioxygenase [E. coli DH5 $\alpha(\mathrm{pDTG} 927)]$ transformed 4A26DNT into a single compound. The BSTFAderivatized product had a retention time of $10.85 \mathrm{~min}$. The mass spectrum was consistent with an aminomethylnitrocatechol (molecular weight, 184) derivatized on the two hydroxyl substituents of the ring (Fig. 3A). Although an amino substituent can be derivatized by trimethylsilane (14), the reaction conditions used here allowed substitution of the protons only on the more reactive hydroxyl substituents. The only catechol isomer that could result from dioxygenation of 4A26DNT and generate the mass spectrum in Fig. 3A is 3-amino-6-methyl-5nitrocatechol.

The recombinant strain carrying the 2,4-DNT dioxygenase from strain DNT [E. coli DH5 $\alpha(\mathrm{pJS} 48)]$ transformed 2A46DNT into a single product. BSTFA derivatization yielded a single compound with a gas chromatography retention time of 10.65 min (Fig. 3B). The mass spectrum of the compound was very similar to that of the product from the nitrobenzene dioxygenase-catalyzed transformation of 4A26DNT (Fig 3A). Either the ortho- or the para-nitro substituent of 2A46DNT could be removed in the reaction to yield three possible dihy- 

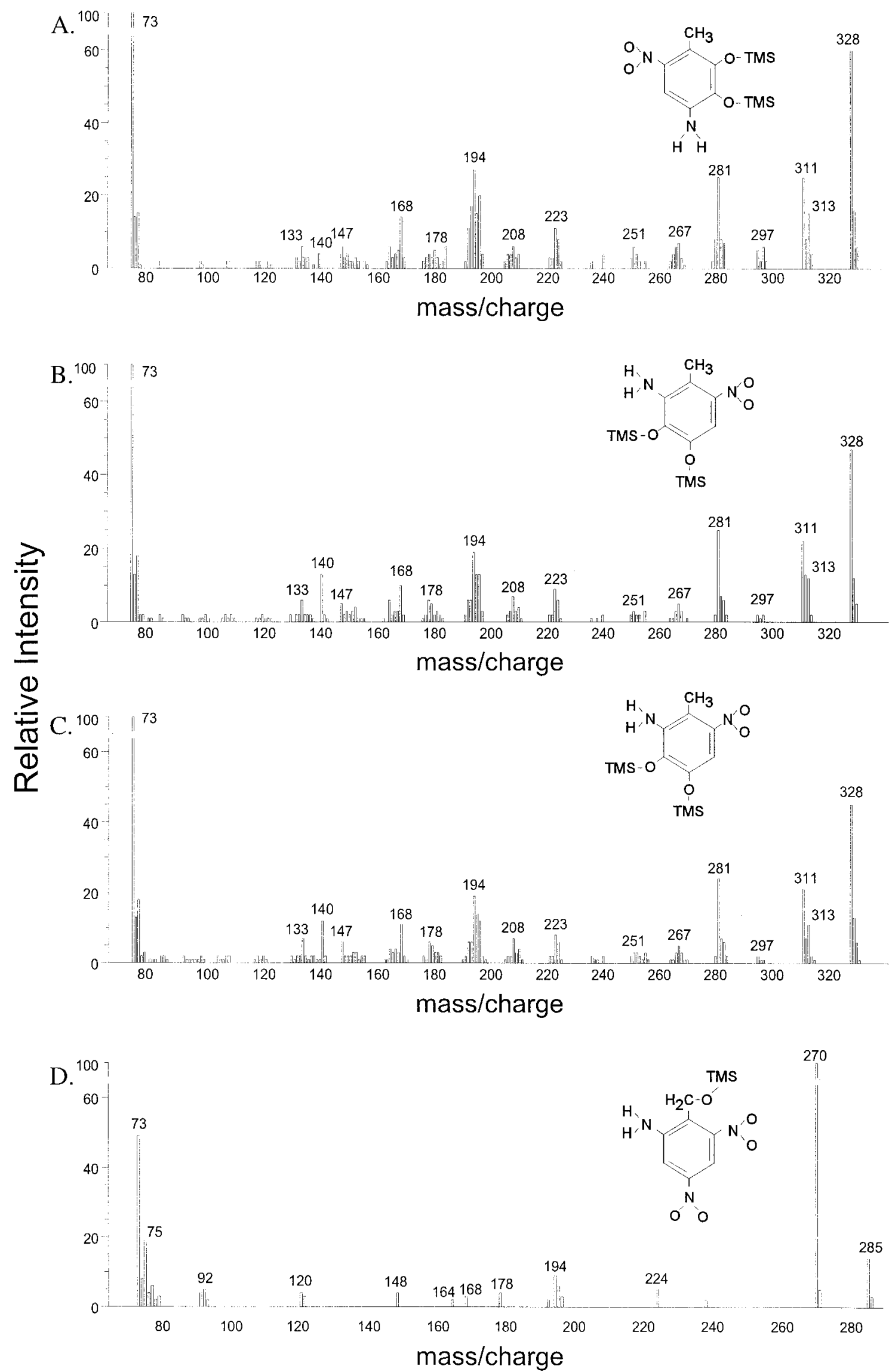

FIG. 3. Mass spectra of metabolites from oxidation of 4A26DNT by nitrobenzene dioxygenase [E. coli DH5 $\alpha(\mathrm{pDTG} 927)]$ (A) and oxidation of $2 \mathrm{~A} 46 \mathrm{DNT}$ by $2,4-\mathrm{DNT}$ dioxygenase [E. coli DH5 $\alpha(\mathrm{pJS} 48)](\mathrm{B})$ or [E. coli DH5 $\alpha(\mathrm{pJS} 1329)](\mathrm{C}$ and D). 
droxy compounds. Because the enzyme was unable to transform and denitrate the 4A26DNT isomer, hydroxylation at the 5,6 position seems improbable. In addition, the 311-amu fragment is $[\mathrm{M}-\mathrm{O}-\mathrm{H}]^{+}$, a fragment characteristic of a nitro group ortho to a methyl group. By analogy to the transformation of 2,4-DNT (Fig. 1C), the most likely product is 3-amino-4-methyl-5-nitrocatechol. Rigorous identification will require nuclear magnetic resonance analysis.

The 2,4-DNT dioxygenase from strain R34 was less specific; it produced two hydroxylated products. The first (Fig. 3C) was identical to the putative 3-amino-4-methyl-5-nitrocatechol produced by the 2,4-DNT dioxygenase from strain DNT (Fig. 3B). The mass spectrum of the second product (Rt 11.2) (Fig. 3D) was consistent with a monohydroxylated aminodinitrotoluene derivatized on the hydroxyl group. Benzylic hydroxylation is often catalyzed by dioxygenases and was shown specifically for nitroarene dioxygenases with various nitroaromatic compounds as substrates (20; Lessner et al., submitted). Accordingly, the second product appears to be 2-amino-4,6-dinitrobenzyl alcohol.

The reaction products were identified by analogy to known compounds and characteristic fragments in their mass spectra. To our knowledge, this is the first report of the aminomethylnitrocatechol isomers. 2-Amino-4,6-dinitrobenzyl alcohol and 4-amino-2,4-dinitrobenzyl alcohol have been chemically synthesized (27). Mass spectra of the underivatized 2-amino4,6-dinitrobenzyl alcohol $\left([\mathrm{M}]^{+} 213,196,179\right)$ from our reactions (not shown) correspond with the major ion fragments reported by Schmidt et al. (27).

The substrate preferences of the dioxygenases can be related to the regiospecific hydroxylation of their physiological substrates. The 2,4-DNT dioxygenases appear to require a nitro group para to the methyl substituent of the ring for the dioxygenase reaction (Fig. 4). The proposed oxidation of 2A46DNT is analogous to the formation of 4-methyl-5-nitrocatechol in the 2,4-DNT pathway. The nitrobenzene dioxygenase showed the opposite specificity. When the amino substituent was in the ortho position, the nitrobenzene dioxygenase only hydroxylated the methyl group by a monooxygenase reaction (Fig. 4). If the amino substituent was in the para position, nitrobenzene dioxygenase catalyzed the typical dioxygenase reaction to form the catecholic product and remove one of the nitro substituents (Fig. 4). So, not unexpectedly, substitutions on the aromatic ring influence the regiospecificity of the oxygenase reaction. It is probable that the substitutions alter the positioning of the substrate in the enzyme active site. Additional studies of the three-dimensional structures of the nitroarene dioxygenases will determine the true basis for the catalytic differences.

To date, no oxygenase enzymes have been shown to attack the aromatic ring of trinitroaromatic compounds. The combination of steric effects from the four ring substituents, along with the electron deficiency of the ring due to the nitro groups, make electrophilic oxidative attack on TNT an extreme challenge. The reduction of one nitro substituent to an amine changes the electronic properties of the compound and allows oxidative transformation. The results of recent work indicate that ligninolytic fungi mineralize ADNTs via an oxidative route, but no degradation intermediates have been identified $(10,36,37)$. Other studies indicated that certain bacteria transform ADNTs to the corresponding benzoic acid derivatives

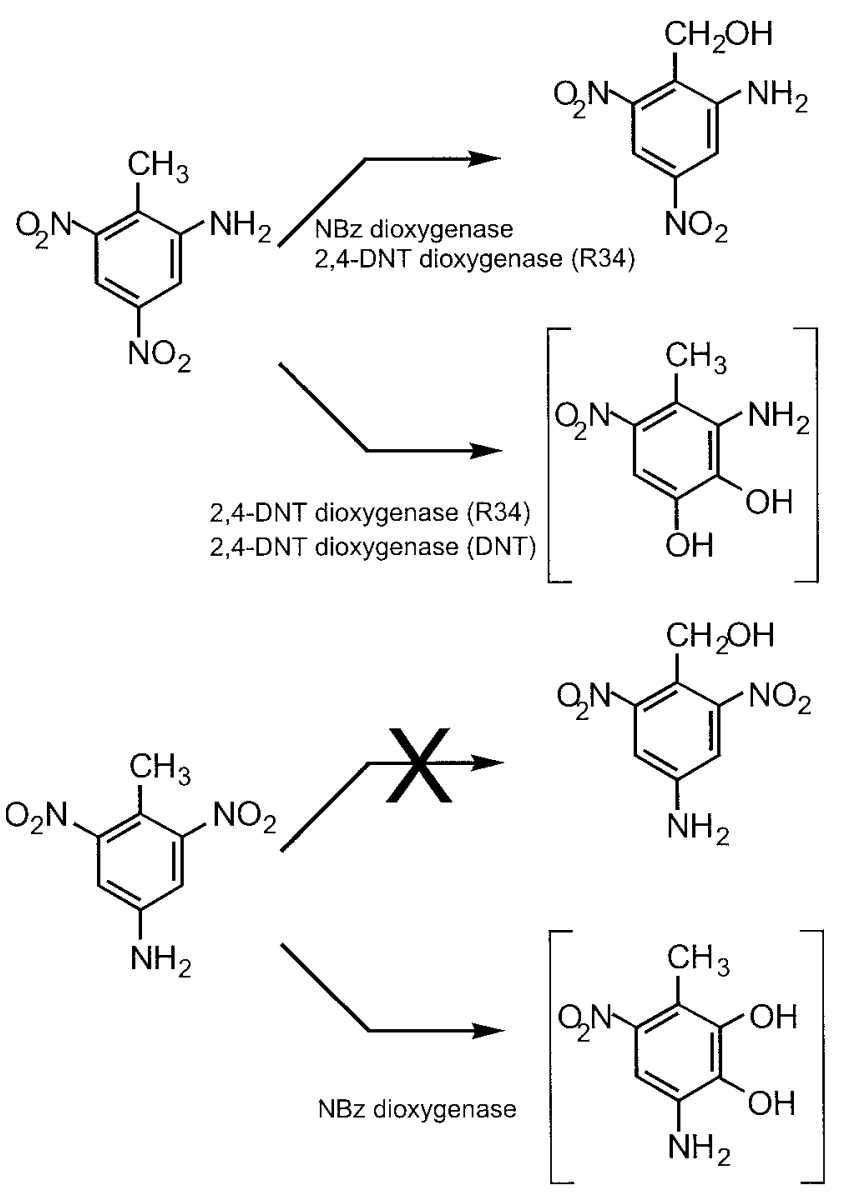

FIG. 4. Dioxygenase-catalyzed oxidation of 2A46DNT and 4A26DNT. NBz, nitrobenzene; X, reaction was not detected.

(38) and other unidentified polar compounds in oxygen-dependent reactions (2). Pseudomonas pseudoalcaligenes JS52 reduces 4A26DNT to 2-hydroxylamino-4-amino-6-nitrotoluene, which is transformed to 4-amino-2-nitroso-6-nitrotoluene and other unidentified compounds in oxygen-dependent reactions (8). Another pathway is used by Clostridium acetobutylicum to hydroxylate the aromatic ring. Two of the nitro groups are reduced to form 2,4-dihydroxylamino-6-nitrotoluene; the para substituent is then reduced to form 4-amino-2-hydroxylamino6-nitrotoluene. The 4-amino-2-hydroxylamino-6-nitrotoluene is subsequently transformed to a compound tentatively identified as 2-amino-5-hydroxy-4-hydroxylamino-6-nitrotoluene (J. Hughes, personal communication). Ozone-mediated oxidation of ADNTs yields nitrate, nitrite, and small organic molecules, including pyruvic and glyoxylic acids (33), which could be assimilated in other biodegradative pathways.

The results presented here reveal that bacterial oxygenases can specifically oxidize ADNT isomers. The findings expand the known substrate ranges of the nitroarene dioxygenases beyond the mono- and dinitrotoluenes. Subsequent degradation of the ADNT oxidation products has not been examined. We plan to discover whether the dihydroxy compounds that result from the dioxygenase reaction are substrates for ring fission enzymes. 


\section{ACKNOWLEDGMENTS}

This work was supported in part by the Air Force Office of Scientific Research and the Strategic Environmental Research and Development Program (Air Force Research Laboratory) and by grants from the National Science Foundation (BES 9702361) and the Air Force Office of Scientific Research (University of Connecticut).

We thank R. Guy Riefler and Ashvini Chauhan for their assistance in preliminary experiments for the project and Ronald Spanggord and Shirley Nishino for their comments during preparation of the manuscript.

\section{REFERENCES}

1. Achtnich, C., E. Fernandes, J.-M. Bollag, H.-J. Knackmuss, and F. Lenke. 1999. Covalent binding of reduced metabolites of $\left[{ }^{15} \mathrm{~N}_{3}\right] \mathrm{TNT}$ to soil organic matter during a bioremediation process analyzed by ${ }^{15} \mathrm{~N}$ NMR spectroscopy. Environ. Sci. Technol. 33:4448-4456.

2. Alvarez, M. A., C. L. Kitts, J. L. Botsford, and P. J. Unkefer. 1995. Pseudomonas aeruginosa strain MA01 aerobically metabolizes the aminodinitrotoluenes produced by 2,4,6-trinitrotoluene nitro group reduction. Can. J. Microbiol. 41:984-991.

3. Bruns-Nagel, D., T. C. Schmidt, O. Drzyzga, E. von Low, and K. Steinbach. 1999. Identification of oxidized TNT metabolites in soil samples of a former ammunition plant. Environ. Sci. Pollut. Res. 6:7-10.

4. Channon, H. J., G. T. Mills, and R. T. Williams. 1944. The metabolism of 2,4,6-trinitrotoluene ( $\alpha$-TNT). Biochem. J. 38:70-85.

5. Daun, G., F. Lenke, M. Reuss, and H.-J. Knackmuss. 1998. Biological treatment of TNT-contaminated soil. I: anaerobic co-metabolic reduction and interaction of TNT and metabolites with soil components. Environ. Sci. Technol. 32:1956-1963.

6. Delgado, A., M. G. Wubbolts, M.-A. Abril, and J. L. Ramos. 1992. Nitroaromatics are substrates for the TOL plasmid upper-pathway enzymes. Appl. Environ. Microbiol. 58:415-417.

7. Esteve-Nunez, A., and J. L. Ramos. 1998. Metabolism of 2,4,6-trinitrotoluene by Pseudomonas sp. JLR11. Environ. Sci. Technol. 32:3802-3808.

8. Fiorella, P. D., and J. C. Spain. 1997. Transformation of 2,4,6-trinitrotoluene by Pseudomonas pseudoalcaligenes JS52. Appl. Environ. Microbiol. 63:20072015.

9. French, C. E., S. Nicklin, and N. C. Bruce. 1998. Aerobic degradation of 2,4,6-trinitrotoluene by Enterobacter cloacae PB2 by pentaerythritol tetranitrite reductase. Appl. Environ. Microbiol. 64:2864-2868.

10. Fritsche, W., K. Scheibner, A. Herre, and M. Hofrichter. 2000. Fungal degradation of explosives: TNT and related nitroaromatic compounds, p. 213-237. In J. C. Spain, J. B. Hughes, and H.-J. Knackmuss (ed.), Biodegradation of nitroaromatic compounds and explosives. Lewis Publishers, Boca Raton, Fla.

11. Haigler, B. E., and J. C. Spain. 1993. Biodegradation of 4-nitrotoluene by Pseudomonas sp. strain 4NT. Appl. Environ. Microbiol. 59:2239-2243.

12. Kalafut, T., M. E. Wales, V. K. Rastogi, R. P. Naumova, S. K. Zaripova, and J. R. Wild. 1998. Biotransformation patterns of 2,4,6-trinitrotoluene by aerobic bacteria. Curr. Microbiol. 36:45-54.

13. Kaplan, D. L., and A. M. Kaplan. 1982. 2,4,6-Trinitrotoluene-surfactant complexes: decomposition, mutagenicity, and soil leaching studies. Environ. Sci. Technol. 16:566-571.

14. Knapp, D. R. 1979. Handbook of analytical derivatization reactions. John Wiley and Sons, New York, N.Y.

15. Lenke, H., C. Achtnich, and H.-J. Knackmuss. 2000. Perspectives of bioelimination of polynitroaromatic compounds, p. 91-126. In J. C. Spain, J. B. Hughes, and H.-J. Knackmuss (ed.), Biodegradation of nitroaromatic compounds and explosives. Lewis Publishers, Boca Raton, Fla.

16. Lenke, H., J. Warrelmann, G. Daun, K. Hund, U. Sieglen, U. Walter, and H.-J. Knackmuss. 1998. Biological treatment of TNT-contaminated soil. 2. Biologically induced immobilization of the contaminants and full scale application. Environ. Sci. Technol. 32:1964-1971.

17. Lewis, T. A., M. M. Ederer, R. L. Crawford, and D. L. Crawford. 1997. Microbial transformation of 2,4,6-trinitrotoluene. J. Ind. Microbiol. Biotechnol. 18:89-96.

18. Lewis, T. A., S. Goszczynski, R. L. Crawford, R. A. Korus, and W. Admassu. 1996. Products of anaerobic 2,4,6-trinitrotoluene (TNT) transformation by
Clostridium bifermentans. Appl. Environ. Microbiol. 62:4669-4674.

19. Nishino, S. F., and J. C. Spain. 1995. Oxidative pathway for the biodegradation of nitrobenzene by Comamonas sp. strain JS765. Appl. Environ. Microbiol. 61:2308-2313.

20. Parales, J. V., R. E. Parales, S. M. Resnick, and D. T. Gibson. 1998. Enzyme specificity of 2-nitrotoluene 2,3-dioxygenase from Pseudomonas sp. strain JS42 is determined by the C-terminal region of the alpha subunit of the oxygenase component. J. Bacteriol. 180:1194-1199.

21. Parales, R., M. Emig, N. Lynch, and D. Gibson. 1998. Substrate specificities of hybrid naphthalene and 2,4-dinitrotoluene dioxygenase enzyme systems. J. Bacteriol. 180:2337-2344.

22. Parales, R. E. 2000. Molecular biology of nitroarene degradation, p. 63-90. In J. C. Spain, E. J. Hughes, and H.-J. Knackmuss (ed.), Biodegradation of nitroaromatic compounds and explosives. Lewis Publishing, Boca Raton, Fla.

23. Pridmore, R. D. 1987. New and versatile cloning vectors with a kanamycinresistance marker. Gene 56:309-312.

24. Renoux, A. Y., M. Sarrazin, J. Hawari, and G. I. Sunahara. 2000. Transformation of 2,4,6-trinitrotoluene in soil in the presence of the earthworm Eisenia andrei. Environ. Toxicol. Chem. 19:1473-1480.

25. Rhys-Williams, W., S. C. Taylor, and P. A. Williams. 1993. A novel pathway for the catabolism of 4-nitrotoluene by Pseudomonas. J. Gen. Microbiol. 139:1967-1972.

26. Robertson, J. B., J. C. Spain, J. D. Haddock, and D. T. Gibson. 1992 Oxidation of nitrotoluenes by toluene dioxygenase: evidence for a monooxygenase reaction. Appl. Environ. Microbiol. 58:2643-2648.

27. Schmidt, T. C., K. Steinbach, U. Buetehorn, K. Heck, U. Volkwein, and G. Stork. 1999. Synthesis of reference substances for highly polar metabolites of nitroaromatic compounds. Chemosphere 38:3119-3130.

28. Smibert, R. M., and N. R. Krieg. 1994. Phenotypic characterization, p. 607-654. In P. Gerhardt, R. G. E. Murray, W. A. Wood, and N. R. Krieg (ed.), Methods for general and molecular bacteriology. American Society for Microbiology, Washington, D. C.

29. Smith, P. K., R. I. Krohn, G. T. Hermanson, A. K. Mallia, F. H. Gartner, M. D. Provenzano, E. K. Fujimoto, N. M. Goeke, B. J. Olson, and D. C. Klenk. 1985. Measurement of protein using bicinchoninic acid. Anal. Biochem. 150:76-85.

30. Spain, J. C. 1995. Biodegradation of nitroaromatic compounds. Annu. Rev. Microbiol. 49:523-555.

31. Spain, J. C., E. J. Hughes, and H.-J. Knackmuss (ed.). 2000. Biodegradation of nitroaromatic compounds and explosives. Lewis Publishers, Boca Raton, Fla.

32. Spanggord, R. J., J. C. Spain, S. F. Nishino, and K. E. Mortelmans. 1991 Biodegradation of 2,4-dinitrotoluene by a Pseudomonas sp. Appl. Environ. Microbiol. 57:3200-3205.

33. Spanggord, R. J., C. D. Yao, and T. Mill. 2000. Oxidation of aminodinitrotoluenes with ozone: products and pathways. Environ. Sci. Technol. 34:497504.

34. Suen, W. C., B. E. Haigler, and J. C. Spain. 1996. 2,4-Dinitrotoluene dioxygenase from Burkholderia sp. strain DNT: similarity to naphthalene dioxygenase. J. Bacteriol. 178:4926-4934.

35. Suen, W. C., and J. C. Spain. 1993. Cloning and characterization of Pseudomonas sp. strain DNT genes for 2,4-dinitrotoluene degradation. J. Bacteriol. 175:1831-1837.

36. Van Aken, B., M. D. Cameron, J. D. Stahl, A. Plumat, H. Naveau, S. D. Aust, and S. N. Agathos. 2000. Glutathione-mediated mineralization of ${ }^{14} \mathrm{C}$-labeled 2-amino-4,6-dinitrotoluene by manganese-dependent peroxidase $\mathrm{H} 5$ from the white-rot fungus Phanerochaete chrysporium. Appl. Microbiol. Biotechnol. 54:659-664.

37. Van Aken, B., K. Skubisz, H. Naveau, and S. N. Agathos. 1997. Biodegradation of 2,4,6-trinitrotoluene (TNT) by the white-rot basidiomycete Phlebia radiata. Biotechnol. Lett. 19:813-817.

38. Vanderberg, L. A., J. J. Perry, and P. J. Unkefer. 1995. Catabolism of 2,4,6-trinitrotoluene by Mycobacterium vaccae. Appl. Microbiol. Biotechnol. 43:937-945.

39. Vasileva, G. K., B.-T. Oh, P. J. Shea, R. A. Drijber, V. D. Kreslavski, R. Minard, and J.-M. Bollag. 2000. Aerobic TNT reduction via 2-hydroxylamino-4,6-dinitrotoluene by Pseudomonas aeruginosa strain MX isolated from munitions-contaminated soil. Biorem. J. 4:111-124. 